\title{
The effects of negative work on the maximal instantaneous muscular power of humans during vertical jumps
}

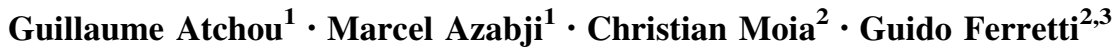

Received: 27 March 2015/Accepted: 21 June 2015/Published online: 14 July 2015

(C) Springer-Verlag Italia 2015

\begin{abstract}
The aim of this study was to test the hypothesis that the maximal instantaneous muscular power of humans $\left(\dot{w}_{\mathrm{p}}\right)$ is affected by the negative work performed immediately before the jump $\left(w_{n}\right)$, possibly due to the recoil of elastic strain energy stored in previously stretched series-elastic elements of the muscle-tendon complex. Twenty-seven Bantu subjects (age $25.1 \pm 4.3$ years, body mass $67.5 \pm 7.8 \mathrm{~kg}$ ) were investigated. The $\dot{w}_{\mathrm{p}}$, the average power $\left(\dot{w}_{\mathrm{a}}\right)$ and $w_{\mathrm{n}}$ were determined during maximal vertical jumps off both feet on a force platform. Three jumping conditions were studied: squat jumps (SQ), countermovement jumps (CM), and jumps preceded by a free fall (FF) from a height of $0.3 \mathrm{~m}$ above the platform surface. The $w_{\mathrm{n}}$ was higher in CM than in SQ and in FF than in CM and SQ. The $\dot{w}_{\mathrm{p}}$ was $3.51 \pm 0.54 \mathrm{~kW}$ in SQ and did not vary in $\mathrm{CM}$ and FF. The $\dot{w}_{\mathrm{a}}$ increased with increasing $w_{\mathrm{n}}(1.70 \pm 0.30 ; 1.85 \pm 0.34 ; 1.99 \pm 0.31 \mathrm{~kW}$ in $\mathrm{SQ}, \mathrm{CM}$ and FF, respectively, $p<0.05)$. The greater was the $w_{\mathrm{n}}$, the higher was the force at the start of the positive push phase, and thus the maximal force attained during the push phase. In conclusion, $\dot{w}_{\mathrm{p}}$ was independent of $w_{\mathrm{n}}$, whereas $\dot{w}_{\mathrm{a}}$ was affected, because a greater force was developed over a shorter time during the push. The independence of $\dot{w}_{\mathrm{p}}$ of $w_{\mathrm{n}}$ leads to refutation of the tested hypothesis.
\end{abstract}

Keywords Jumping $\cdot$ Elastic energy $\cdot$ Mechanical power

Guido Ferretti

Guido.Ferretti@unige.ch

1 Faculté de Médecine et des Sciences Biomédicales, Yaoundé, Cameroun

2 Département APSI, Université de Genève, 1 rue Michel Servet, CH-1211 Genève 4, Switzerland

3 Health and Wealth at Unibs, University of Brescia, Viale Europa 11, I-25123 Brescia, Italy

\section{Introduction}

The amount of positive work done by a muscle stimulated supramaximally is increased when its performance is immediately preceded by that of negative work [11]. By analogy, when a series of extensions from a squatting position is performed, the energy cost of the exercise is lower and the mechanical efficiency higher, if each extension is immediately preceded by a flexion than if it is not [33]. The current interpretation of these findings implies that a considerable amount of elastic energy, stored in the stretched series-elastic elements of a muscle-tendon complex during flexion (negative work), is recoiled during extension (positive work), thus contributing to power development. This would improve the overall mechanical efficiency of the exercise. Indeed, such mechanisms appear to explain the considerably high efficiency of running in humans [10].

Coherently with this view, when the performance of a maximal jump on a force platform is immediately preceded by a countermovement, the vertical displacement of the centre of gravity during the jump is higher than that attained during a similar maximal jump performed without countermovement, starting from a squatting position $[2$, 12]. The displacement of the centre of gravity is further increased if the jump is preceded by a free fall from given heights above the platform's surface [2]. Indeed, it was shown that tendon stiffness contributes to the extra-height attained during countermovement jumps [29, 35], although this view is not unanimously shared [4].

Ferretti et al. [21] proposed that the maximal instantaneous muscular power $\left(\dot{w}_{\mathrm{p}}\right)$ and the maximal average power $\left(\dot{w}_{\mathrm{a}}\right)$ during a vertical jump on a force platform are indexes of, respectively, the maximal rate of ATP splitting and the maximal rate of ATP resynthesis from the 
Lohmann reaction by the contracting muscles. However, in order for this to be so, two assumptions must be made: (1) that all the fibres from the contracting muscle mass be simultaneously active during the few milliseconds of $\dot{w}_{\mathrm{p}}$ development; and (2) that no recoil of elastic energy accumulated during a phase of negative work $\left(w_{\mathrm{n}}\right)$ immediately preceding the jump takes place. The former assumption could not be tested so far in humans, and relies essentially on the observation that the values of work per mole of ATP split estimated from the $\dot{w}_{\mathrm{p}}$ decrease found during jumps performed from an exercise baseline [21] were very similar to those measured on isolated muscle preparations [19]. The latter assumption is generally contoured by asking the subjects to perform jumps starting from a squatting position, in order to reduce the performance of $w_{\mathrm{n}}$ to a minimum. This choice carries along the implicit notion that there is a positive relation between $w_{\mathrm{n}}$ and $\dot{w}_{\mathrm{p}}$.

To our knowledge, however, no systematic investigation of the effects of $w_{\mathrm{n}}$ on $\dot{w}_{\mathrm{p}}$ was carried out so far. Asmussen and Bonde Petersen [2] did not measure $\dot{w}_{\mathrm{p}}$ in their study. Although several further studies on the elastic mechanisms during jumping can be found in the literature $[1,3,5,6,8,26,31,34,36]$, in none of them $\dot{w}_{\mathrm{p}}$ values are reported. A higher $\dot{w}_{\mathrm{a}}$ in countermovement than in squatting pushes with a sledge device was reported, but no determinations of $\dot{w}_{\mathrm{p}}$ were carried out in the same study [36]. Zamparo et al. [37] found that the force at the time instant at which velocity becomes positive during the jump is a direct function of $w_{\mathrm{n}}$, and thus that the positive work and the $\dot{w}_{\mathrm{a}}$ during the push phase of the jump are affected by $w_{\mathrm{n}}$. They also reported a positive effect of $w_{\mathrm{n}}$ on $\dot{w}_{\mathrm{p}}$, but the worth of these results, however, is undermined by the fact that their observations were made on a very narrow range of $w_{\mathrm{n}}$ values, since they tried to avoid any countermovement prior to jump. Conversely, to the best of our knowledge, all studies aimed at determining $\dot{w}_{\mathrm{p}}$ were carried out without any countermovement, thus without any measure of $w_{\mathrm{n}}[7,15,17,20-24,27]$. A combination of squatting and countermovement jumps was recently investigated, but the range of $w_{\mathrm{n}}$ values was not such as to allow the establishment of a relationship between $\dot{w}_{\mathrm{p}}$ and $w_{\mathrm{n}}$ [13]. In the only study carried out on African natives, only average power determined with Margaria's test was measured [18].

We therefore carried out the present study, the aim of which was to test the hypothesis that $\dot{w}_{\mathrm{p}}$, as well as $\dot{w}_{\mathrm{a}}$, is affected by the performance of $w_{\mathrm{n}}$ immediately prior to the jump. To this aim, the $w_{\mathrm{n}}$ range was expanded by performing countermovement jumps or jumps preceded by free falls onto the platform.

\section{Methods}

The experiments were carried out on a total of 27 Bantu subjects (age $25.1 \pm 4.3$ years, body mass $67.5 \pm 7.8 \mathrm{~kg}$ ), of whom 21 were males and 6 females. The experiments were performed at Yaoundé Medical School, Cameroon, with equipment transported from Geneva. Ethical approval for this protocol was obtained in Geneva. All subjects signed an informed consent form before entering the study, and were adequately trained to the jumping techniques before they performed the experimental jumps.

The $\dot{w}_{\mathrm{p}}$ was determined during maximal vertical jumps off both feet on a force platform, as proposed by Davies and Rennie [16]. Three jumping conditions were investigated: squat jumps (SQ), with the subject keeping his knees at approximately $90^{\circ}$; countermovement jumps (CM), with the subject starting from a vertical standing posture; and jumps preceded by a free fall (FF) from a height of $0.3 \mathrm{~m}$ above the surface of the platform. In this case, the maximal upward jump was performed immediately after landing on the platform, without stopping, and the subjects were instructed and trained to bounce on landing while immediately pushing upward. During the jumps, the subjects kept his hands on his hips. Ten jumps were performed for each condition, separated by a 1 min interval to avoid any fatigue effect. The jump yielding the maximal $\dot{w}_{\mathrm{p}}$ value was then retained.

The force signal was sampled at an acquisition frequency of $100 \mathrm{~Hz}$. The time course of the changes of the vertical forces during the jump was monitored by eight strain gauges located at the four corners of the platform. Data acquisition was carried out by a digital acquisition system (Biopac, USA) and stored in a computer. From the force tracings, acceleration $(a)$ at any time instant $\mathrm{t}$ was calculated as:

$a(t)=F(t) \cdot M^{-1}-g$,

where $F$ is the force exerted on the platform along the $y$ axis, $M$ is the subject's mass and $g$ is the gravity acceleration. The corresponding vertical velocity of the centre of gravity $(v)$ was then calculated as the time integral of $a$. The power $(\dot{w})$ at time $t$ was calculated as:

$\dot{w}(t)=F(t) \cdot v(t)$.

The maximal calculated value of $\dot{w}(t)$ was retained as the $\dot{w}_{\mathrm{p}}$ developed during the jump [21]. The negative work $\left(w_{\mathrm{n}}\right)$ was calculated as the time integral of $\dot{w}$ during the flexion phase (negative $v$ ) of the jump. The positive work $\left(w_{\mathrm{p}}\right)$ was calculated as the time integral of $\dot{w}$ during the push phase of the jump (positive $v$ ). The $\dot{w}_{\text {a }}$ was also determined as the integral mean of the time course of $\dot{w}$ during the push (positive $v$ ). 
In addition, from the force tracings, two force values were retained for further analysis: the maximal force attained during the push phase $\left(F_{\max }\right)$, and the force reached at the time instant of the first positive velocity value, i.e. when positive work starts (initial force, $F_{\text {ini) }}$ ). From the velocity tracings, two values were retained too: the maximal velocity attained during the push phase $\left(v_{\max }\right)$, and the velocity at the time instant when $F$ falls to 0 at start of flight (take-off velocity, $v_{\mathrm{t} 0}$ ). An example of $F, v$ and $\dot{w}$ tracings from a jump is shown in Fig. 1. Kinetic energy $\left(E_{\mathrm{k}}\right)$ was then computed as:

$E_{\mathrm{k}}=\frac{M v^{2}}{2}$

using both $v_{\max }$ and $v_{\mathrm{t} 0}$ values. The vertical displacement of the centre of gravity during the flight $\left(d_{\mathrm{f}}\right)$ was then calculated as:

$d_{\mathrm{f}}=\frac{v_{\mathrm{t} 0}^{2}}{2 g}$.

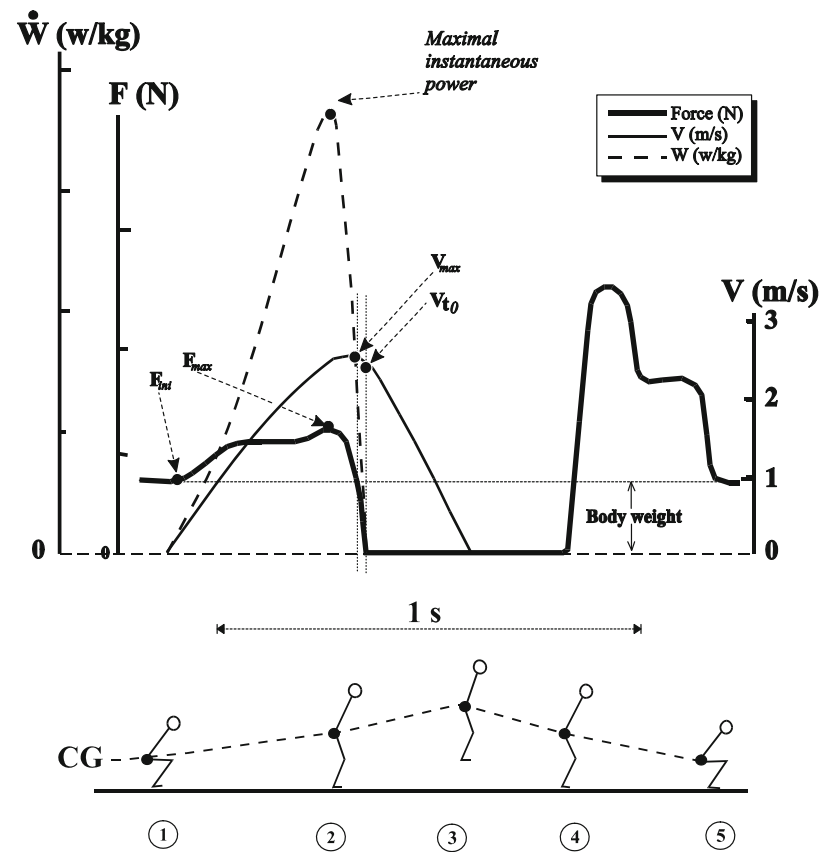

Fig. 1 Example of the evolution of force ( $F$, thick line), velocity ( $v$, thin line) and power ( $\dot{w}$,dashed line) as a function of time, and thus of the subject's position depicted on the bottom, during a maximal vertical jump from the squatting position on a force platform. Before the jump, the subject stands still on the platform, and the recorded $F$ is equal to his body weight. Then the push phase starts, $F$ increases above body weight: an increase in $v$ and $\dot{w}$ takes place up to a maximum. Toward the end of the push, $F$ decreases rapidly, to attain a zero value during the flight. Maximum velocity $\left(v_{\max }\right)$ is attained at the time instant when $F$, during its decrease, becomes again equal to the body weight. Velocity at take off $\left(v_{\mathrm{t} 0}\right)$ is thus slightly lower than $v_{\max }$. The maximal instantaneous power value is indicated on the figure, as are the maximal force $\left(F_{\max }\right)$ and the force recorded at the start of the positive push phase $\left(F_{\text {ini }}\right)$

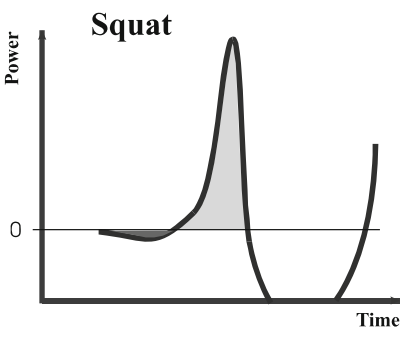

Counter movement

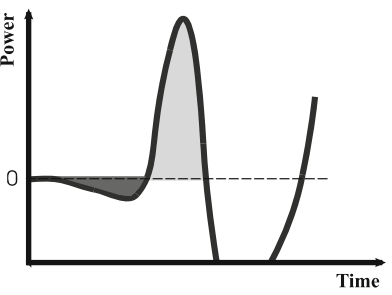

Free fall from $30 \mathrm{~cm}$
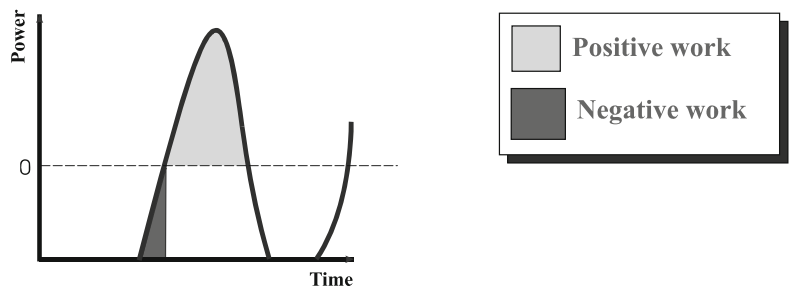

Fig. 2 Drawings indicating the typical evolution of power during maximal vertical jumps off both feet on a force platform carried out from a squatting position, with a countermovement and immediately after a free fall from a height of $0.3 \mathrm{~m}$. Areas depicting negative and positive work are evidenced

When the jump is carried out from the squatting position, and the subject starts pushing upward, $a$ and $v$ immediately take positive values, and only positive work is performed. In the case of a countermovement, the subject moves downward before pushing upward, negative $a$ and $v$ values are observed before the positive push phase, and the performance of negative work precedes that of positive work. When a jump is preceded by a fall from a $0.3 \mathrm{~m}$ height, during the free-fall phase, $a=-g$. Thus, at the time instant when the subject touches the platform, he has a negative $v\left(-2.42 \mathrm{~m} \mathrm{~s}^{-1}\right)$, which he has to brake before pushing upward for the subsequent jump: negative work is performed prior to the positive work. An example of the time course of $\dot{w}$, with indication of the corresponding negative and positive work, is presented in Fig. 2.

Differences between the three investigated conditions were analysed by one-way ANOVA. Differences were considered significant when $p<0.05$. When significant interactions were found, a post hoc test (Tukey's test) was applied for an evaluation of differences between the three jumping conditions. Linear relationships were computed by the least square method. Differences between slopes were investigated by ANOVA.

\section{Results}

The power values obtained in this study are summarized in Table 1 . The $w_{\mathrm{n}}$ was obviously higher in CM than in SQ and in FF than in CM and SQ. The $\dot{w}_{\mathrm{p}}$ did not differ in the 
Table 1 Negative work and positive peak and average powers during the jumps

\begin{tabular}{|c|c|c|c|c|c|c|c|c|c|c|c|c|c|c|}
\hline & \multicolumn{2}{|c|}{$\begin{array}{l}\text { Negative work } \\
\text { (J) }\end{array}$} & \multicolumn{2}{|c|}{$\begin{array}{l}\text { Peak power } \\
(\mathrm{kW})\end{array}$} & \multicolumn{2}{|c|}{$\begin{array}{l}\text { Speed at peak power } \\
\left(\mathrm{m} \mathrm{s}^{-1}\right)\end{array}$} & \multicolumn{2}{|c|}{$\begin{array}{l}\text { Force at peak } \\
\text { power }(\mathrm{kN})\end{array}$} & \multicolumn{2}{|c|}{$\begin{array}{l}\text { Peak power } \\
\left(\mathrm{W} \mathrm{kg}^{-1}\right)\end{array}$} & \multicolumn{2}{|c|}{$\begin{array}{l}\text { Average power } \\
(\mathrm{kW})\end{array}$} & \multicolumn{2}{|c|}{$\begin{array}{l}\text { Average power } \\
\left(\mathrm{W} \mathrm{kg}^{-1}\right)\end{array}$} \\
\hline & $X$ & SD & $X$ & SD & $X$ & SD & $X$ & SD & $X$ & SD & $X$ & SD & $X$ & SD \\
\hline SQ & 23.4 & 22.3 & 3.51 & 0.54 & 2.35 & 0.11 & 1.49 & 0.21 & 52.0 & 5.3 & 1.70 & 0.34 & 25.3 & 4.4 \\
\hline $\mathrm{CM}$ & $285.0^{\mathrm{a}}$ & 58.2 & 3.35 & 0.55 & 2.33 & 0.09 & 1.44 & 0.24 & 49.6 & 5.9 & 1.85 & 0.30 & 27.4 & 3.1 \\
\hline $\mathrm{FF}$ & $455.5^{\mathrm{a}, \mathrm{b}}$ & 54.5 & 3.43 & 0.51 & 2.22 & 0.13 & 1.55 & 0.20 & 50.9 & 6.3 & $1.99 *$ & 0.31 & $29.5^{*}$ & 3.6 \\
\hline
\end{tabular}

$S Q$ jump from a squatting position, $C M$ jump preceded by a countermovement, $F F$ jump preceded by a free fall from the height of $0.3 \mathrm{~m}$

a Significantly different from SQ

b Significantly different from CM

Table 2 Force, speed and flight time during the jumps

\begin{tabular}{|c|c|c|c|c|c|c|c|c|c|c|}
\hline & \multicolumn{2}{|c|}{$F_{\text {ini }}(\mathrm{kN})$} & \multicolumn{2}{|c|}{$F_{\max }(\mathrm{kN})$} & \multicolumn{2}{|c|}{$v_{\max }\left(\mathrm{m} \mathrm{s}^{-1}\right)$} & \multicolumn{2}{|l|}{$T_{\mathrm{f}}(\mathrm{s})$} & \multicolumn{2}{|l|}{$d_{\mathrm{f}}(\mathrm{m})$} \\
\hline & $X$ & SD & $X$ & SD & $X$ & SD & $X$ & SD & $X$ & $\mathrm{SD}$ \\
\hline SQ & 0.12 & 0.11 & 1.60 & 0.21 & 2.72 & 0.15 & 0.537 & 0.035 & 0.315 & 0.064 \\
\hline $\mathrm{CM}$ & 1.12 & 0.29 & 1.77 & 0.26 & 2.79 & 0.15 & 0.557 & 0.037 & 0.335 & 0.039 \\
\hline FF & 1.16 & 0.31 & 2.12 & 0.29 & 2.89 & 0.19 & 0.557 & 0.043 & 0.333 & 0.037 \\
\hline
\end{tabular}

$F_{i n i}$ force at the beginning of positive work during the push phase, $F_{\max }$ maximal force during the push phase, $v_{\max }$ maximal speed during the push phase, $t_{f}$ flight time, $d_{f}$ distance travelled by centre of mass during flight, $S Q$ jump from a squatting position, $C M$ jump preceded by a countermovement, $F F$ jump preceded by a free fall from the height of $0.3 \mathrm{~m}$

three investigated conditions. The $\dot{w}_{\mathrm{a}}$ increased significantly with increasing $w_{\mathrm{n}}$. Thus the $\dot{w}_{\mathrm{a}} / \dot{w}_{\mathrm{p}}$ ratio was $0.49 \pm 0.07,0.55 \pm 0.04$ and $0.58 \pm 0.05$ in $\mathrm{SQ}, \mathrm{CM}$ and $\mathrm{FF}$, respectively, the values in $\mathrm{CM}$ and FF being significantly higher than those in SQ.

The determinants of $\dot{w}_{\mathrm{p}}$ and $\dot{w}_{\mathrm{a}}$ are presented in Table 2 . The greater was the $w_{\mathrm{n}}$, the higher was the force at the start of the positive push phase (end of stretch, $F_{\text {ini }}$ ). As a consequence, the maximal force $\left(F_{\max }\right)$ attained during the push phase was significantly higher in CM than in SQ, and in FF than in CM and SQ. Also the maximal speed $\left(v_{\max }\right)$ was higher the greater the $w_{\mathrm{n}}$. Thus, the kinetic energy $\left(E_{\mathrm{k}}\right)$ at the beginning of the flight increased with $w_{\mathrm{n}}(252 \pm 45$, $264 \pm 46$ and $283 \pm 45 \mathrm{~J}$, in SQ, CM and FF, respectively, the last value being significantly different from the first). The flight time was $537 \pm 35,557 \pm 37$ and $557 \pm 43 \mathrm{~ms}$, in SQ, CM and FF, respectively. This tendency to increase, however, was not significant.

The relation between force and $w_{\mathrm{n}}$ is shown in Fig. 3 . Both the maximal force during the push phase $\left(F_{\max }\right)$, and the force attained at the beginning of the push phase $\left(F_{\text {ini }}\right)$ are reported. Significant linear relations appear, such that the greater is the absolute amount of $w_{\mathrm{n}}$, the higher are $F_{\max }$ and $F_{\text {ini }}$. The slope of the line for $F_{\max }$ is not significantly different from that of the line for $F_{\text {ini. }}$. The relation between power and $w_{\mathrm{n}}$ is presented in Figs. 4 and 5. As expected from the data shown in Table 1, $\dot{w}_{\mathrm{p}}$ (Fig. 4) resulted unaffected by $w_{\mathrm{n}}(p>0.1)$, whereas $\dot{w}_{\mathrm{a}}$ (Fig. 5) was significantly related to $w_{\mathrm{n}}$.

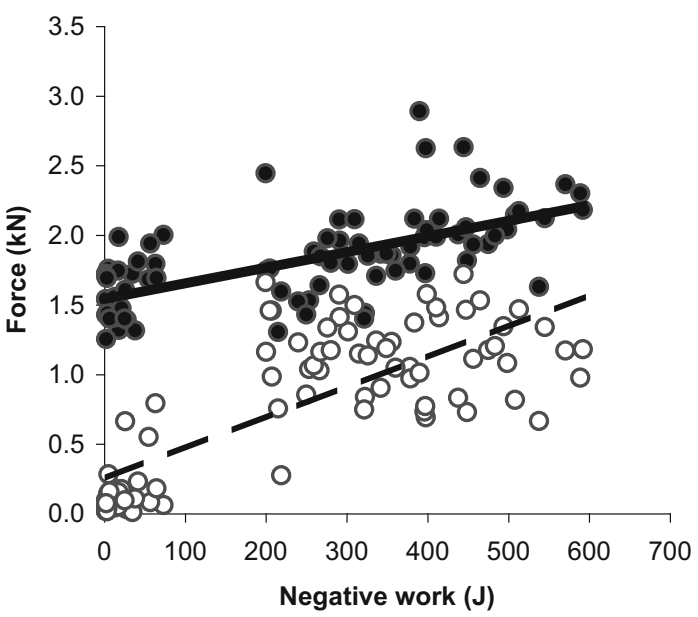

Fig. 3 Force as a function of negative work. Both the maximal force attained during the push phase (filled dots, upper line) and the initial force, i.e. the force at the beginning of the push phase (open dots, lower line $)$, are reported. Regressions lines $(n=27$ in all cases $)$ are: $y=0.0011 \times x+1.545, r=0.6317, p<0.0001$ and $y=0.0022 \times$ $x+0.2523, r=0.7764, p<0.0001$, for maximal and initial force, respectively. The lines for maximal force have significantly higher $y$ intercepts than those for initial force. The slopes of the two lines are not significantly different between them

\section{Discussion}

This study was carried out to test the hypothesis that $\dot{w}_{\mathrm{p}}$, as well as $\dot{w}_{\mathrm{a}}$, is affected by the performance of $w_{\mathrm{n}}$ immediately prior to the jump. The main finding of this study was, 
Fig. 4 Peak power as a function of negative work. No significant relationship between these two parameters was found $(y=0.00005 \times x+3.4245$, slope significantly equal to zero, $n=27$ )

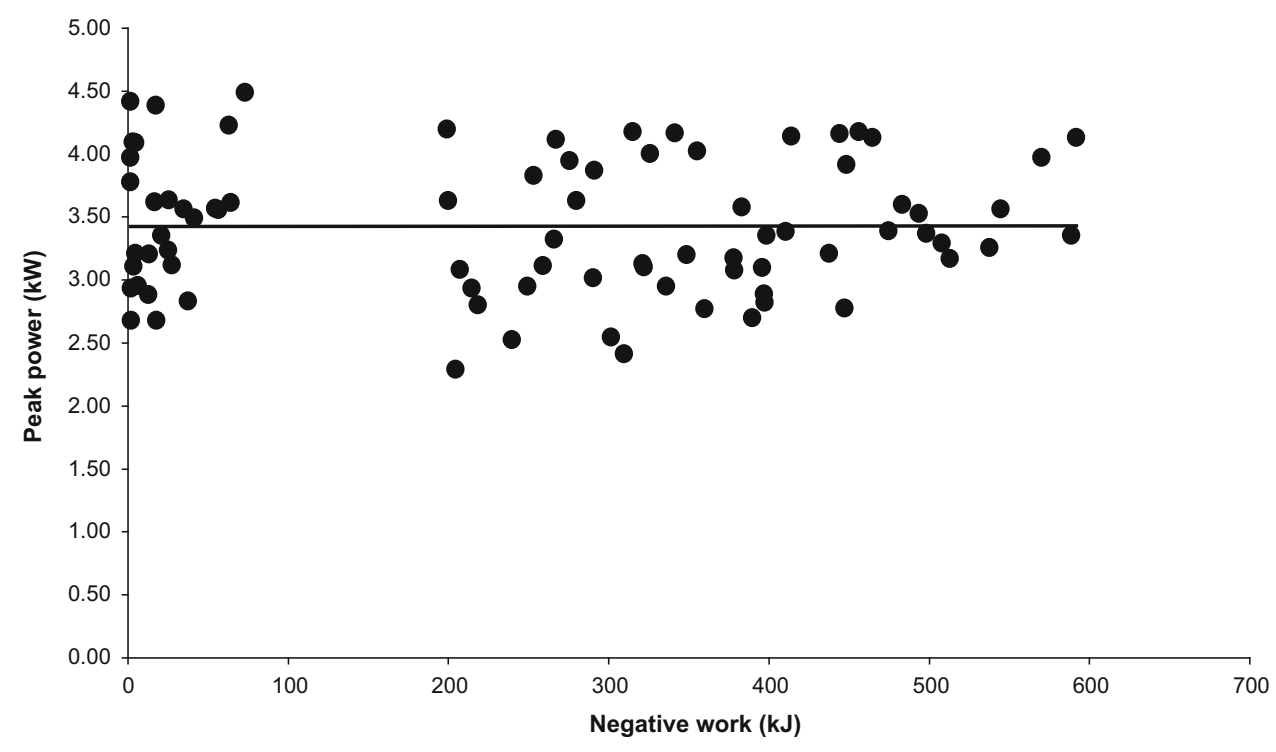

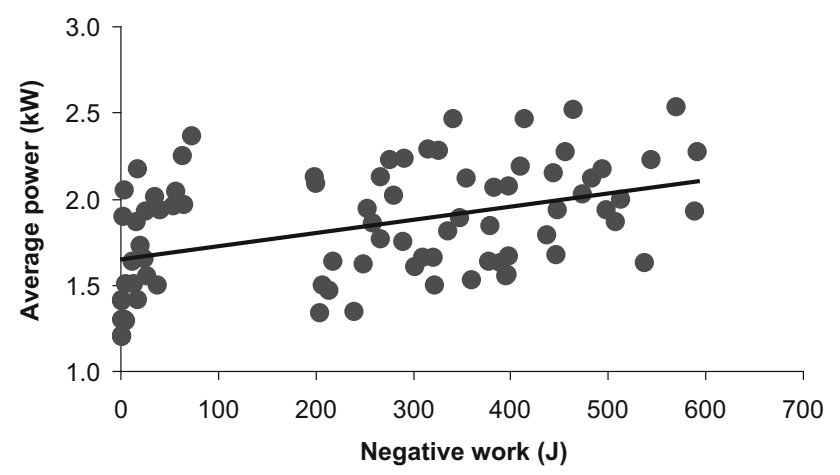

Fig. 5 Average power as a function of negative work. The regression line $(n=27)$ is: $y=0.0008 \times x+1.653, r=0.4264$, with significant positive slope and intercept $(p<0.01)$

however, that only $\dot{w}_{\mathrm{a}}$ was affected by $w_{\mathrm{n}}, \dot{w}_{\mathrm{p}}$ being independent of it. Thus, these results lead to the refutation of the tested hypothesis. These results reinforce the hypothesis that $\dot{w}_{\mathrm{p}}$ is an expression of the maximal rate of ATP splitting in the contracting muscles [21], by validating one of the assumptions behind it. Indeed, the $\dot{w}_{\mathrm{p}}$ independence of $w_{\mathrm{n}}$ indicates that this hypothesis can be reasonably extended to countermovement jumps and free-fall jumps. Practically speaking, this means that, if a mere analysis of $\dot{w}_{\mathrm{p}}$ is to be performed, there is no need to instruct a subject to avoid countermovements prior to the jump.

By analogy with $\dot{w}_{\mathrm{p}}, \dot{w}_{\mathrm{a}}$ was claimed to reflect the rate of ATP resynthesis from the Lohmann reaction [21]. The finding that $\dot{w}_{\mathrm{a}}$ depends on $w_{\mathrm{n}}$ obviously restricts the applicability of this assumption to a condition in which the performance of $w_{\mathrm{n}}$ immediately before the jump is carefully avoided. An energetic analysis of $\dot{w}_{\mathrm{a}}$ along this line requires that the jumps performed for the measurement of $\dot{w}_{\mathrm{a}}$ be performed from a squatting position. The value of this claim, however, has been partially diminished by the recent observation that, over the time of $\dot{w}_{\mathrm{a}}$ development, ATP resynthesis may also occur via anaerobic glycolysis, in agreement with the glycogen shunt theory [32].

These results are at variance with those obtained by Zamparo et al. [37], who reported that $\dot{w}_{\mathrm{p}}$ was significantly affected by $w_{\mathrm{n}}$. However, they performed their study with a sledge device which tends per se to minimize the performance of $w_{\mathrm{n}}$ prior to the push phase. So they could investigate only a very narrow range of $w_{\mathrm{n}}$ values, some 20-30 times smaller than that investigated in the present study. Their range was probably too small to allow an accurate analysis of the effects of $w_{\mathrm{n}}$ on $\dot{w}_{\mathrm{p}}$.

When a subject bends downward, as during the countermovement preceding the jump, he brakes the body fall. In the resulting performance of negative work, his tendons are stretched, as demonstrated by the recent direct evidence of Achilles tendon elongation during plantar flexion [28]. It is admitted that by so doing they accumulate elastic strain energy, which is utilized during an immediate subsequent performance of positive work [33]. This notion implies that, at the time instant when the positive work is initiated-start of the push phase in case of vertical jumps - the exerted force $\left(F_{\text {ini }}\right)$ be greater if positive work is preceded by negative work than if it is not [12]. This is indeed the case for the present subjects, as Fig. 3 shows a positive relation of $F_{\text {ini }}$ to $w_{\mathrm{n}}$. As a consequence, higher forces and accelerations are developed during the entire push phase. It is also possible that stretch reflexes and inhibition from Golgi tendon organs may contribute to this phenomenon [14].

Figure 3 shows also that the slope of the relationship between $F_{\max }$ and $w_{\mathrm{n}}$ is not significantly different from that of the relationship between $F_{\text {ini }}$ and $w_{\mathrm{n}}$. This means that the 
increase in force above $F_{\text {ini }}$ during the push phase $\left(F_{\max }-\mathrm{F}_{\text {ini }}\right)$ is invariant. Thus the increase in $F_{\max }$ observed in CM and FF with respect to SQ can be attributed to a change in $F_{\text {ini }}$, with no contribution from stronger concentric contractions during the push phase. This finding is coherent with the observation by others that there is a positive linear relationship between $F_{\text {ini }}$ and the average force during the push phase [8]. It is thus possible to conclude that the changes in $F_{\text {max }}$ observed in $\mathrm{CM}$ and $\mathrm{FF}$ are a direct consequence of the recoil of elastic strain energy accumulated in stretched tendons during the performance of $w_{\mathrm{n}}$. Contradictory with this notion, however, is the observation (Table 1 ) that $F_{\text {ini }}$ did not differ between $\mathrm{CM}$ and FF. The jumps carried out with $\mathrm{FF}$ require a higher degree of neural coordination than those with CM and SQ. This may have prevented the achievement of maximal motor unit activation in the present FF jumps. If this was so, the positive effects of increased $w_{\mathrm{n}}$ performance on $F_{\text {ini }}$, and ultimately on the jump's height, would have been at least partially counteracted by lesser neural activation.

Obviously enough, greater $F_{\text {ini }}$ and $F_{\text {max }}$ values in CM and FF imply higher accelerations during the entire push phase. However, because of the invariant length of body segments, these accelerations are applied for a shorter time in CM and FF than in SQ, in accordance with the observation that the duration of the push phase is longest in SQ and shortest in FF. As a consequence, the average power attained during the push phase is increased with respect to that attained in SQ. Indeed in the present study (see Table 1) $\dot{w}_{\text {a }}$ was significantly higher in CM than in SQ and in FF than in CM and SQ. This finding is in agreement with the observations of Zamparo et al. [36] during maximal pushes on a sledge. Coherently, Fig. 5 shows a significant positive relation between $\dot{w}_{\mathrm{a}}$ and $w_{\mathrm{n}}$. Related to the increase in $\dot{w}_{\mathrm{a}}$ are also the progressively higher $v_{\max }, v_{\mathrm{t} 0}$ and $d_{\mathrm{f}}$ values when moving from SQ to $\mathrm{CM}$ and from this to FF, with a tendency to increase the flight time. Coherently, a progressive increase in $d_{\mathrm{f}}$ as a function of $w_{\mathrm{n}}$ was often observed by others [2, 25, 29-31, 34]. However, if the duration of the positive push phase was shorter in FF than in SQ, this change in $\dot{w}_{\mathrm{a}}$ might have occurred without a corresponding change in positive (concentric) work. The amount of positive work done to move the body from its lowest position on the platform to its take-off position (potential energy component) and to accelerate the body (kinetic energy component) during the push phase (positive work) is constrained by the geometry of lower limbs. This justifies the assertion that it may not have varied in this study.

The improvement of the jump's height in CM and SQ occurs with no contribution from $\dot{w}_{\mathrm{p}}$. Concerning this last, its occurrence in fact takes place at an earlier time during the push phase in CM and in FF than in SQ, because of the greater acceleration values. Although in $\mathrm{CM}$ and in FF the higher $F_{\text {ini }}$ displaces the force curve upward during the push, the simultaneous anticipation of the $\dot{w}_{\mathrm{p}}$ attainment implies that $\dot{w}_{\mathrm{p}}$ is the result either of a higher force coupled with a lower velocity or of unchanged force and velocity. Of course velocity keeps going up during the push phase; however, its maximal value is attained while force is already decreasing prior to take off.

Two limitations are to be acknowledged. One concerns the fact that we did not control the knee angle during the jump, in order to avoid possible interferences with $\dot{w}_{\mathrm{p}}$ attainment. Although this may not be a problem for SQ and $\mathrm{CM}$, the push phase of which has likely started at about the same knee angles, this is certainly not the case for FF. The effects of different knee angles was conveniently investigated by Zamparo et al. [36] using a sledge apparatus. Their results suggest the possibility that the $\dot{w}_{\mathrm{a}}$ attained during FF might have been lower than it would have been in case of a push phase starting at equal knee angles as in $\mathrm{CM}$ and SQ. The second limitation, applicable to all studies implying determinations of $\dot{w}_{\mathrm{p}}$, concerns the impossibility of establishing, by means of EMG recordings, the muscle activation patterns of the muscles that contract during the push phase of the jumps. The assumption is that, at the time instant when it is attained, all muscle fibres are recruited simultaneously [21]. The concept of maximal anaerobic alactic power relies on this assumption, which is a reasonable yet still undemonstrated assumption.

In conclusion, the results of the present study show that $\dot{w}_{\mathrm{p}}$ is independent of the prior performance of $w_{\mathrm{n}}$. Conversely, $\dot{w}_{\mathrm{a}}$ increases with $w_{\mathrm{n}}$, because a greater force is developed over a shorter time during the push. The $\dot{w}_{\mathrm{p}}$ independence of $w_{\mathrm{n}}$ allows application of the energetic interpretation of $\dot{w}_{\mathrm{p}}$, stating that $\dot{w}_{\mathrm{p}}$ reflects the maximal rate of ATP splitting, not only to squatting jumps, but also to countermovement jumps. We can thus propose that $\dot{w}_{\mathrm{p}}$, as well as the maximal rate of ATP splitting [9], ought to depend on the rate of acto-myosin interaction, which is determined by the myosin isoform expressed in a given muscle fibre.

Acknowledgments This study was supported by a cooperation grant between the University of Geneva School of Medicine and the Yaoundé Medical School, Cameroon.

Conflict of interest There is no conflict of interest for this study

Ethical standard Ethical approval for this study was provided by HUG ethical committee, Geneva, in support of the cooperation programme between University of Geneva and Faculté de Médecine et Sciences Biomédicales, Yaoundé, Cameroun.

Informed consent Only literate subjects were admitted to the study, in order to obtain written informed consent. 


\section{References}

1. Anderson FC, Pandy MG (1993) Storage and utilization of elastic strain energy during jumping. J Biomech 26:1413-1427

2. Asmussen E, Bonde-Petersen F (1974) Storage of elastic energy in skeletal muscles in man. Acta Physiol Scan 91:385-392

3. Bobbert MF (2001) Dependence of human squat jump performance on the series elastic compliance of the triceps surae: a simulation study. J Exp Biol 204:533-542

4. Bobbert MF, Gerritsen KG, Litjens MC, Van Soest AJ (1996) Why is countermovement jump height greater than squat jump height? Med Sci Sport Exerc 28:1402-1412

5. Bobbert MF, Mackay M, Schinkelshoek D, Huijing PA, van Ingen Schenau GJ (1986) Biomechanical analysis of drop and countermovement jumps. Eur J Appl Physiol 54:566-573

6. Bosco C, Komi PV (1979) Potentiation of the mechanical behaviour of the human skeletal muscle through prestretching. Acta Physiol Scand 106:467-472

7. Bosco C, Komi P (1980) Influence of aging on the mechanical behavior of leg extensor muscles. Eur J Appl Physiol 45:209-219

8. Bosco C, Tihanyi J, Latteri F, Fekete G, Apor P, Rusko H (1986) The effect of fatigue on store and re-use of elastic energy in slow and fast types of human skeletal muscle. Acta Physiol Scand 128:109-117

9. Bottinelli R (2001) Functional heterogeneity of mammalian single muscle fibres: do myosin isoforms tell the whole story? Pflügers Arch 443:6-17

10. Cavagna GA (1977) Storage and utilisation of elastic energy in skeletal muscle. Exerc Sport Sci Rev 5:89-129

11. Cavagna GA, Dusman B, Margaria R (1968) Positive work done by a previously stretched muscle. J Appl Physiol 24:21-32

12. Cavagna GA, Komarek L, Citterio G, Margaria R (1971) Power output of the previously stretched muscle. Med Sport Turin 6:159-167

13. Cè E, Margonato V, Casasco M, Veicsteinas A (2008) Effects of stretching on maximal anaerobic power: the roles of active and passive warm-ups. J Strength Cond Res 22:794-800

14. Chalmers G (2004) Re-examination of the possible role of Golgi tendon organ and muscle spindle reflexes in proprioceptive neuromuscular facilitation muscle stretching. Sport Biomech 3:159-183

15. Davies CTM (1971) Human power output in exercise of short duration in relation to body size and composition. Ergonomics $14: 245-256$

16. Davies CTM, Rennie R (1968) Human power output. Nature 217:770-771

17. Davies CTM, White MJ (1983) Contractile properties of elderly human triceps surae. Gerontology 29:19-25

18. di Prampero PE, Cerretelli P (1969) Maximal muscular power (aerobic and anaerobic) in African natives. Ergonomics 12:51-59

19. di Prampero PE, Meyer M, Cerretelli P, Piiper J (1981) Energy sources and mechanical efficiency of anaerobic work in dog's gastrocnemius. Pflügers Arch 389:257-262

20. Ferretti G, Berg HE, Minetti AE, Moia C, Narici MV (2001) Maximal instantaneous muscular power after prolonged bed rest in humans. J Appl Physiol 90:431-435
21. Ferretti G, Gussoni M, di Prampero PE, Cerretelli P (1987) Effects of exercise on maximal instantaneous muscular power of humans. J Appl Physiol 62:2288-2294

22. Ferretti G, Hauser H, di Prampero PE (1990) Muscular exercise at high altitude. VII. Maximal muscular power before and after exposure to chronic hypoxia. Int J Sport Med 11:S31-S34

23. Ferretti G, Ishii M, Moia C, Cerretelli P (1992) Effects of temperature on the maximal instantaneous muscle power of humans. Eur J Appl Physiol 64:112-116

24. Ferretti G, Narici MV, Binzoni T, Gariod L, Le Bas JF, Reutenauer H, Cerretelli P (1994) Determinants of peak muscle power: effects of age and physical conditioning. Eur J Appl Physiol 68:111-115

25. Fukashiro S, Komi PV, Järvinen M, Miyashita M (1995) In vivo Achilles tendon loading during jumping in humans. Eur $\mathbf{J}$ Appl Physiol 71:453-458

26. Horita T, Komi PV, Nicol C, Kyröläinen H (2002) Interaction between pre-landing activities and stiffness regulation of the knee joint musculoskeletal system in the drop jump: implications to performance. Eur J Appl Physiol 88:76-84

27. Grassi B, Cerretelli P, Narici MV, Marconi C (1991) Peak anaerobic power in master athletes. Eur J Appl Physiol 62:394-399

28. Kawakami Y, Muraoka T, Ito S, Kanehisa H, Fukunaga T (2002) In vivo muscle fibre behaviour during counter-movement exercise in humans reveals a significant role for tendon elasticity. J Physiol Lond 540:635-646

29. Kubo K, Kawakami Y, Fukunaga T (1999) Influence of elastic properties of tendon structures on jump performance in humans. J Appl Physiol 87:2090-2096

30. Kurokawa S, Fukunaga T, Fukashiro S (2001) Behavior of fascicles and tendinous structures of human gastrocnemius during vertical jumping. J Appl Physiol 90:1349-1358

31. Luhtanen P, Komi PV (1980) Force-, power-, and elasticity-velocity relationships in walking, running and jumping. Eur $\mathrm{J}$ Appl Physiol 44:279-289

32. Shulman RG, Rothman DS (2001) The "glycogen shunt" in exercising muscle: a role for glycogen in muscle energetics and fatigue. Proc Natl Acad Sci USA 98:457-461

33. Thys H, Faraggiana T, Margaria R (1972) Utilization of muscle elasticity in exercise. J Appl Physiol 32:491-494

34. Voigt M, Simonsen EB, Dyhre-Poulsen P, Klausen K (1995) Mechanical and muscular factors influencing the performance in maximal vertical jumping after different prestretch loads. J Biomech 28:293-307

35. Walshe AD, Wilson GJ, Murphy AJ (1996) The validity and reliability of a test of lower body musculotendinous stiffness. Eur J Appl Physiol 73:332-339

36. Zamparo P, Antonutto G, Capelli C, di Prampero PE (2000) Effects of different after-loads and knee angles on maximal explosive power of the lower limbs in humans. Eur J Appl Physiol 82:381-390

37. Zamparo P, Antonutto G, Capelli C, Girardis M, Sepulcri L, di Prampero PE (1997) Effects of elastic recoil on maximal explosive power of the lower limbs. Eur J Appl Physiol 75:289-297 